\title{
Risk for depression affects older people's possibilities to exercise self-determination in using time, social relationships and living life as one wants: A cross-sectional study with frail older people
}

\author{
Isabelle Ottenvall Hammar, 1,2 Helene Berglund,1,3 Synneve Dahlin-Ivanoff,,2 \\ Joel Faronbi, ${ }^{1,4}$ Susanne Gustafsson ${ }^{1,2}$ \\ ${ }^{1}$ The Frail Elderly Research Support Group, Institute of Neuroscience and Physiology, the \\ Sahlgrenska Academy at Gothenburg University, Gothenburg, Sweden; ${ }^{2}$ The Gothenburg \\ University Centre for Ageing and Health, Gothenburg, Sweden; ${ }^{3}$ Institute of Health and Care \\ Sciences, the Sahlgrenska Academy at Gothenburg University, Gothenburg, Sweden; ${ }^{4}$ Department \\ of Nursing Science, College of Health Science, Obafemi Awolowo University, Ile-Ife, Nigeria
}

\begin{abstract}
Exercising self-determination in daily life is highly valued by older people. However, being in the hands of other people may challenge the older people's possibilities to exercise self-determination in their daily life. Among frail older people living in Sweden, risk for depression is highly predominant. There is a knowledge gap regarding if, and how having a risk of depression affects older people's self-determination. The objective was, therefore, to explore if, and in that case how, frail older people's self-determination is affected by the risk of depression. In this cross-sectional, secondary data analysis, with 161 communitydwelling frail older people, simple logistic regression models were performed to explore the association between self-determination,
\end{abstract}

\footnotetext{
Correspondence: Isabelle Ottenvall Hammar, The Sahlgrenska Academy at the University of Gothenburg, Institute of Neuroscience and Physiology, Department of Health and Rehabilitation, Box 455, SE 40530 Gothenburg, Sweden.

Tel.: +46.031.7865719.

E-mail: isabelle.o-h@neuro.gu.se
}

Key words: Aged, decision-making, depression, person-centredness.

Acknowledgments: This study was supported by the Swedish Research Council for Health, Working Life and Welfare (AGECAP 2013-2300), The Varrdal Institute, the Swedish Institute for Health Sciences, and Vinnvård. We also want to thank the older persons who participated in this study. Trial registration: ClinicalTrials.gov: NCT01260493.

Contributions: IOH was the primary author of the manuscript. IOH and SG were engaged in the data analysis. All authors contributed to the writing of the paper and approved it for publication.

Conflict of interest: the authors declare no conflict of interests.

Received for publication: 24 May 2018.

Accepted for publication: 31 July 2018.

This work is licensed under a Creative Commons AttributionNonCommercial 4.0 International License (CC BY-NC 4.0).

(C) Copyright I. Ottenvall Hammar et al., 2018

Licensee PAGEPress, Italy

Health Psychology Research 2018; 6:7577

doi:10.4081/hpr.2018.7577 the risk of depression and demographic variables. The findings showed that risk for depression and reduced self-determination were significantly associated in the dimensions: use of time $(\mathrm{P}=0.020)$, social relationship $(\mathrm{P}=0.003)$, help and support others $(\mathrm{P}=0.033)$, and the overall self-determination item $(\mathrm{P}=0.000)$. Risk for depression significantly affected self-determination in use of time $(\mathrm{OR}=3.04, \mathrm{P}=0.014)$, social relationship $(\mathrm{OR}=2.53$, $\mathrm{P}=0.011)$, and overall self-determination $(\mathrm{OR}=6.17, \mathrm{P}=0.000)$. This point out an increased need of strengthening healthcare professionals' perspectives, and attitudes towards a self-determined, friendly, and person-centred dialogue.

\section{Introduction}

As a natural course of the aging process, older people may become dependent on others when performing activities of daily living (ADL) (Holstein, Due, Almind, \& Avlund, 2007). Being in the hands of other people may challenge the older person's possibilities to exercise self-determination in his/her daily life (Breitholtz, Snellman, \& Fagerberg, 2013; Ekdahl, Andersson, Wirehn, \& Friedrichsen, 2011; Janlöv, Hallberg, \& Petersson, 2006). Self-determination refers to a process of having control and ethical/legal rights, and the ability and knowledge to make decisions of own free choice (Ekelund, Dahlin-Ivanoff, \& Eklund, 2014). It is important for one's subjective experience of health and well-being (Andersson, Pettersson, \& Sidenvall, 2007; Flick, Fischer, Neuber, Schwartz, \& Walter, 2003; Levasseur, St-Cyr Tribble, \& Desrosiers, 2009). To exercise self-determination in daily life is also highly valued by older people (Breitholtz et al., 2013).

Along with an increased need for help to perform daily activities, the older population is often described as a vulnerable, frail group. According to Fried et al. (2004) frailty can be defined as a physiologic state of increased vulnerability to stressors, as a result of deterioration of physiological reserves, and dysregulation in multiple physiological systems. The presence of chronic medical conditions may in turn increase the probability of developing a depression (Lee, Choi, \& Lee, 2001). Recently, a study (Faronbi, Gustafsson, Berglund, Ottenvall Hammar, \& Dahlin-Ivanoff, 2017) revealed that approximately $30 \%$ of a sample with Swedish pre-frail, and frail people 65 years and older were at risk of depression. Thus, the risk for depression is highly predominant among frail older people living in Sweden. 
Worldwide, about $7 \%$ of people aged 60 years and older experiences depression. The World Health Organization (WHO) (2016) stresses the importance of improving mental health in old age by promoting active and healthy ageing. This could be achieved by proving social support and enabling the right to freedom (WHO, 2016). Older people, as well as younger people, should have freedom to do what they want to do, and to be what they want to be, and to live their lives by what they value, i.e. their capabilities should be acknowledged (Robeyns, 2005). Depression in old age can lead to great suffering since it increases perceptions of poor health (WHO, 2016). Perceptions of reduced self-determination also results in poor self-rated health (Ottenvall Hammar, DahlinIvanoff, Wilhelmson, \& Eklund, 2016). To our knowledge, there is a knowledge gap regarding if, and if that case how having a risk of depression affects older people's self-determination.

To ensure that older people can exercise self-determination in their daily life, their self-determination could be assessed using psychometrically tested assessments. The statements in the Impact on Participation and Autonomy- Older persons (IPA-O) (OttenvallHammar I, Ekelund C, Wilhelmson K, \& Eklund K, 2014), captures older people's perceptions of their opportunities to decide in their daily life regarding mobility, self-care, activities in and around the house, financial situation, use of time, social relationship, help and support others, and living life as one wants. Previously, the IPA-O was used to explore explanatory factors for reduced self-determination in daily life among older people, showing that high education, frailty, poor self-rated health, dissatisfaction with physical health, and receiving help from public homecare service were significantly associated with reduced self-determination (Ottenvall Hammar et al., 2016). Still, there is a lack of knowledge concerning frail older people's self-determination and risk for depression. To enable for healthcare professionals to strengthen frail older people's self-determination, the dimensions of selfdetermination that may be affected by the risk of depression must be further explored. Thus, the aim of this study was to explore if, and in that case how, frail older people's self-determination is affected by the risk of depression.

\section{Materials and Methods}

\section{Design and sample}

In this cross-sectional, secondary analysis, baseline data from the randomised non-blinded controlled trial Continuum of care for frail elderly people (Wilhelmson et al., 2011) were used. The sample consisted of a total of 161 community-dwelling older people who sought care at the Emergency Department at Mölndal Hospital, Sweden, and who were discharged to their own homes in the municipality. People aged 80 years and older, or aged 65 years and older with at least one chronic disease and dependent in at least one activity of daily living were included. Exclusion criteria were a severe acute illness with immediate need of assessment and treatment by a physician, dementia/severe cognitive impairment, and palliative care. The study was approved by the Regional Ethical Review Board in Gothenburg, ref.nr: 413-08.

\section{Data collection}

The data collection consisted of structured face-to-face interviews following a specific study questionnaire in the participants' homes between the beginning of October 2008 to November 2011. The study questionnaire included several questions and measures such as demographic data, symptoms, quality of care, medication, functional ability, self-determination, morbidity/disability, and depression. All interviews were performed by research assistants with different backgrounds (occupational therapy, physiotherapy or registered nurse), that were trained in assessing, interviewing, and observing older people. Study protocol meetings were held regularly to ensure standardization. In this study, only baseline data from the interviews were used.

\section{Assessments}

\section{Dependent variables}

Self-determination in daily life was assessed using the statements from the Swedish Impact on Participation and AutonomyOlder persons (IPA-O) (Ottenvall-Hammar I et al., 2014). IPA-O has been tested for validity and test-retest reliability for persons 70 years and older (Ottenvall-Hammar I et al., 2014). The IPA-O captures older people's perceptions of their opportunities to decide in their daily life. In total, the IPA-O consists of 22 items, which are divided in the following seven dimensions: mobility (4 items), self-care (5 items), activities in and around the house (4 items), financial situation (1 item), use of time (1 item), social relationship (5 items), help and support others (1 item), and one summary item. The IPA-O has five response options: "totally agree", "partly agree", "neither agree nor disagree", "disagree", and "totally disagree" (Ottenvall-Hammar I et al., 2014). People's level of selfdetermination was dichotomized into either perceiving self-determination when they assessed totally agree in all items within the dimension, or perceiving reduced self-determination when they assessed as partly agree, neither agree nor disagree, disagree, and totally disagree in at least one of the items within the dimension.

\section{Independent variables}

The risk for depression was assessed using the Swedish version of the Global Depression Scale (GDS) - 20 (Brink et al., 1982; Gottfries, Noltorp, \& Norgaard, 1997; Yesavage et al., 1982), which is a 20 -item self-reporting scale designed specifically for rating depression in older people. The two answer alternatives "yes" or "no" are given, where an answer with "yes" represents 1 point on a score ranging from 0 to 20 points. People scoring more than 5 points are rated as having a risk for depression.

Depending on the number of participants perceiving reduced self-determination in each dimension of the IPA-O, the demographic variables of gender, living alone and high age (age 80 years and older) were used in the logistic regression models when possible.

\section{Statistical analyses}

Chi-Square and Fisher's exact test was initially carried out with the dichotomous variables to explore the characteristics of participants, and the association between self-determination, the risk of depression and demographic variables. Simple logistic regression models were performed to explore the dependent and independent variables. A P-value of 0.05 was considered significant, and a $95 \%$ confidence interval is provided for analysis when appropriate. Statistical analyses were performed using IBM SPSS version 22.0 (IBM Corporation, Armonk, NY, USA). 


\section{Results}

\section{Demographics}

The majority of the 161 participants were 80 years and older (76\%), age range between 66-96 years. Fifty-five percent $(n=89)$ were women, and $58 \%$ lived alone $(n=94)$. Twenty-two percent $(n=14)$ had tertiary education, $73 \%(n=117)$ were frail, $54 \%$ $(n=35)$ rated their health as good, and half of the sample $(n=80)$ perceived their overall self-determination as good. Seven percent $(n=11)$ had reduced cognition, and almost half of the sample were in risk for depression $(n=71)$ (Table 1).

\section{Perceptions of reduced self-determination}

Approximately half of the participants perceived their selfdetermination as reduced in the dimension of help and support others, and in the overall self-determination item. Thirty-six percent perceived reduced self-determination in social relationships. Only a few participants perceived reduced self-determination in financial situations (6\%) (Table 2).

\section{Reduced self-determination, risk for depression and demographic variables}

The risk for depression was significantly associated with reduced self-determination in the dimensions of use of time

Table 1. Characteristics of participants.

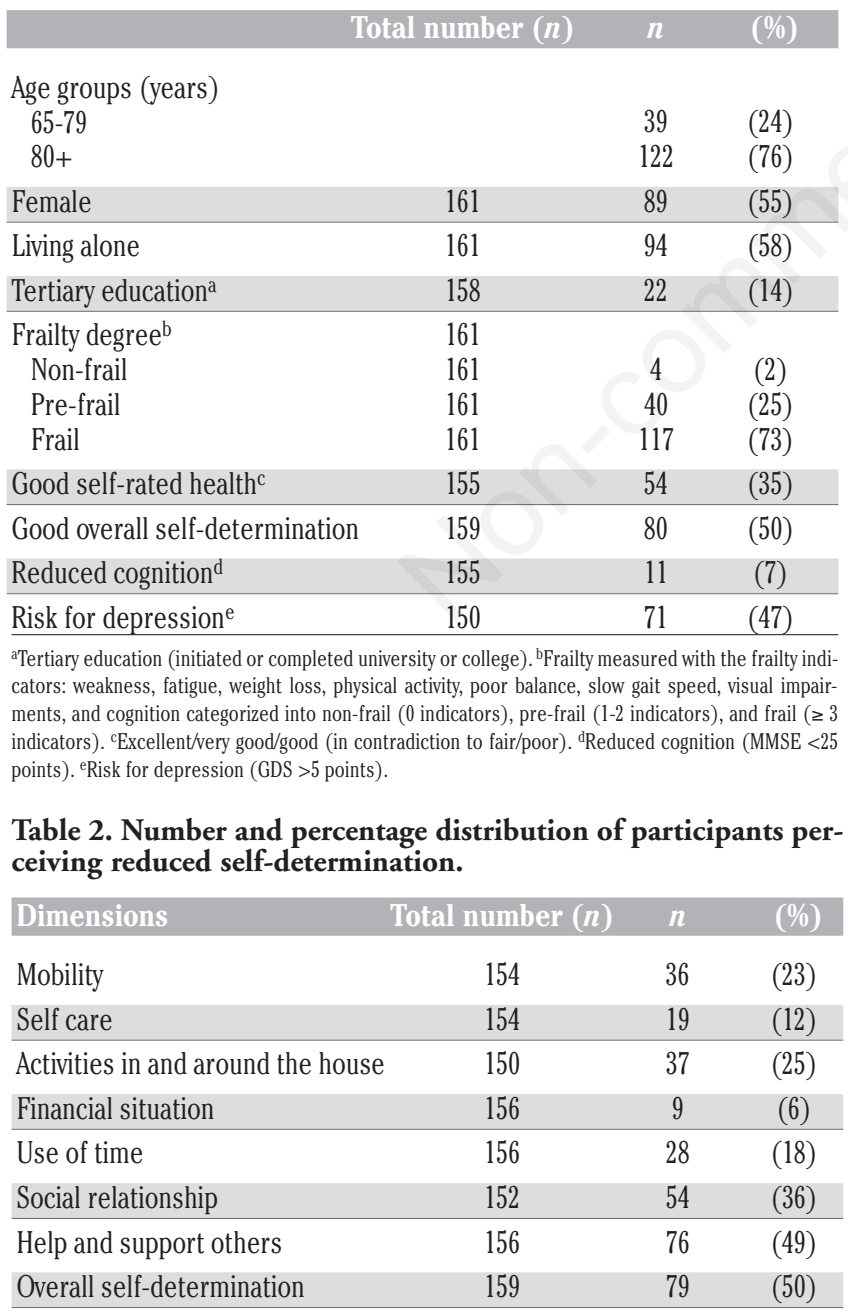

( $\mathrm{P}=0.020)$, social relationship $(\mathrm{P}=0.003)$, help and support others $(\mathrm{P}=0.033)$, and the overall self-determination item $(\mathrm{P}=0.000)$. The demographic variable high age was significantly associated with reduced self-determination in financial situation $(\mathrm{P}=0.044)$, use of time ( $\mathrm{P}=0.028)$, and social relationship $(\mathrm{P}=0.018)$ (Table 3$)$.

Table 3. Association between perceiving reduced self-determination and risk for depression and demographic variables.

\begin{tabular}{|c|c|c|c|}
\hline & \multicolumn{2}{|c|}{ Reduced self-determination } & P-value \\
\hline \multicolumn{4}{|c|}{ Mobility } \\
\hline Risk for depression & 21 & $(14)$ & 0.124 \\
\hline Gender (male) & 13 & (8) & 0.342 \\
\hline Living alone & 21 & $(14)$ & 1.000 \\
\hline High age $(80 \geq)$ & 24 & $(16)$ & 0.188 \\
\hline \multicolumn{4}{|c|}{ Self care } \\
\hline Risk for depression & 11 & (7) & 0.328 \\
\hline Gender (male) & 10 & (6) & 0.462 \\
\hline Living alone & 10 & (6) & 0.630 \\
\hline High age $(80 \geq)$ & 10 & (6) & 0.025 \\
\hline \multicolumn{4}{|c|}{ Activities in and around the house } \\
\hline Risk for depression & 18 & $(13)$ & 0.850 \\
\hline Gender (male) & 15 & (10) & 0.704 \\
\hline Living alone & 25 & (17) & 0.250 \\
\hline High age $(80 \geq)$ & 24 & (16) & 0.123 \\
\hline \multicolumn{4}{|c|}{ Financial situation } \\
\hline Risk for depression & 6 & (4) & 0.307 \\
\hline Gender (male) & 7 & (4) & 0.079 \\
\hline Living alone & 5 & (3) & 1.000 \\
\hline High age $(80 \geq)$ & 4 & (3) & 0.044 \\
\hline \multicolumn{4}{|c|}{ Use of time } \\
\hline Risk for depression & 19 & $(13)$ & 0.020 \\
\hline Gender (male) & 13 & $(8)$ & 0.836 \\
\hline Living alone & 16 & (10) & 1.000 \\
\hline High age $(80 \geq)$ & 16 & $(10)$ & 0.028 \\
\hline
\end{tabular}

\begin{tabular}{lccc} 
Risk for depression & 34 & $(23)$ & 0.003 \\
Gender (male) & 24 & $(16)$ & 1.000 \\
\hline Living alone & 34 & $(22)$ & 0.309 \\
High age $(80 \geq)$ & 34 & $(22)$ & 0.018 \\
\hline
\end{tabular}

\begin{tabular}{lccc} 
Risk for depression & 41 & $(28)$ & 0.033 \\
Gender (male) & 33 & $(21)$ & 0.873 \\
\hline Living alone & 49 & $(31)$ & 0.146 \\
High age $(80 \geq)$ & 55 & $(35)$ & 0.467 \\
\hline
\end{tabular}

\begin{tabular}{llll} 
Risk for depression & 51 & $(34)$ & 0.000 \\
Gender (male) & 32 & $(20)$ & 0.426 \\
\hline Living alone & 51 & $(33)$ & 0.148 \\
High age $(80 \geq)$ & 57 & $(36)$ & 0.361 \\
\hline
\end{tabular}




\section{Logistic regression models}

A number of logistic regression models were performed to explore the impact risk of depression had on perceived self-determination. Risk for depression significantly affected self-determination in use of time $(\mathrm{OR}=3.04, \mathrm{P}=0.014)$, social relationship $(\mathrm{OR}=2.53, \mathrm{P}=0.011)$, and overall self-determination $(\mathrm{OR}=6.17$, $\mathrm{P}=0.000)$. Neither of the demographic variables had any significant effect on perceptions of reduced self-determination (Table 4).

\section{Discussion}

This secondary analysis demonstrated that risk for depression affected the frail older people's possibilities to exercise self-determination in the dimensions of using leisure time, social relationship and one's chances to living the life one wants. Frail older people in risk of depression had three times higher odds of perceiving reduced self-determination concerning their chances to use leisure time the way they wanted. Moreover, the frail older people at risk of depression had two and a half times higher odds of perceiving reduced self-determination in social relationship when compared with people not being at risk for depression. Perceptions of reduced self-determination were also identified among people in risk for depression regarding living life as one wants. In this particular overall level of self-determination, the odds of perceiving reduced self-determination was more than six times higher when comparing with people not in risk of depression. Thus, the present study supports that being in risk of depression affects people's perceptions of self-determination in many aspects in old age. Depression in advanced age is a globally issue (WHO, 2016), the findings from the present study should therefore be taken seriously. Healthcare professionals ought to promote actions towards an active, and healthy ageing in old age (WHO, 2016), including shedding light on the older people's capabilities, which means focusing on what older people are able to do and to be, and what they value (Robeyns, 2005). We argue that focusing on older people's capabilities means shifting from viewing older people as diseased and disabled, towards viewing them as people with important knowledge of themselves and strengths, which are parts that shape the equal partnerships between the people involved. In doing so, it is important to recognize that older people are a heterogeneous group, and that individual preferences always need to be considered. Such a perspective requires a person-centered approach to care, where each people's experiences and feelings are just as important as the professionals (Ekman et al., 2011; McCormack \& McCance, 2006). This approach also puts emphasizes on shared decision-making (Ekman et al., 2011; McCormack \& McCance, 2006), which in turn is favorable for the older people's possibilities to exercise self-determination in daily life.

Self-determination has earlier been illustrated as a relational phenomenon among the older people, which both could be enhanced or reduced depending on the relation between the persons involved in an activity (Ottenvall Hammar, Dahlin-Ivanoff, Wilhelmson, \& Eklund, 2014). In the present study, participants in risk of depression perceived their self-determination as reduced in social relations. This dimension comprises self-determination in relationships regarding conversations with people close to one self, as well as being respected from these people. A significant proportion of the older population needs assistance when performing ADL, and often the help are given by home care services. Healthcare professionals offering the frail older people services with activities of daily living, therefore, have a central role in navigating the people to take control over their life. This implies an increased need of strengthening healthcare professionals' perspectives, and attitudes towards a self-determined friendly dialogue when offering frail older people home care services.

Some methodological issues in this study need to be highlighted. In this cross-sectional, secondary analysis, the older people's self-determination was assessed using the statements from the Impact on Participation and Autonomy-Older persons (IPA-O) (Ottenvall-Hammar I et al., 2014). Before performing the analyses, the 22 items in the IPA-O were dichotomised into seven dimensions and one summary item. The participant's level of self-determination was dichotomized into perceiving self-determination only when they rated "totally agree" in all items within the specific dimension, and the remaining four response options (partly agree, neither agree nor disagree, disagree, and totally disagree) were dichotomised into perceiving reduced self-determination. This nar-

Table 4. Logistic regression with B, Odds Ratio (OR), $95 \%$ Confidence Interval (CI) and p-value of perceiving reduced selfdetermination and risk for depression and demographic variables.

\begin{tabular}{lcccc} 
& B & OR & $95 \%$ CI & P-value \\
& Mobility & & & \\
Risk for depression & 0.72 & 2.04 & $0.93-4.48$ & 0.074 \\
Gender (male) & -0.48 & 0.62 & $0.26-1.46$ & 0.271 \\
\hline Living alone & -0.35 & 0.71 & $0.30-1.67$ & 0.428 \\
\hline \multicolumn{5}{c}{ Self care } \\
Risk for depression & 0.54 & 1.71 & $0.65-4.54$ & 0.279 \\
\hline \multicolumn{4}{r}{ Activities in and around the house } \\
\hline
\end{tabular}

\begin{tabular}{lcccc} 
Risk for depression & 0.30 & 1.03 & $0.48-2.21$ & 0.939 \\
Gender (male) & 0.05 & 1.05 & $0.46-2.37$ & 0.909 \\
\hline Living alone & 0.48 & 1.62 & $0.69-3.79$ & 0.268
\end{tabular}

\begin{tabular}{|c|c|c|c|c|}
\hline Risk for depression & 0.87 & 2.38 & $0.57-9.88$ & 0.234 \\
\hline \multicolumn{5}{|c|}{ Use of time } \\
\hline Risk for depression & 1.11 & 3.04 & $1.25-7.36$ & 0.014 \\
\hline Living alone & -0.28 & 0.76 & $0.32-1.79$ & 0.526 \\
\hline
\end{tabular}

\begin{tabular}{lcccc} 
Risk for depression & 0.93 & 2.53 & $1.23-5.19$ & 0.011 \\
Gender (male) & 0.12 & 1.13 & $0.52-2.44$ & 0.759 \\
\hline Living alone & 0.22 & 1.24 & $0.56-2.72$ & 0.593 \\
High age $(80 \geq)$ & -0.72 & 0.49 & $0.22-1.06$ & 0.069 \\
\hline \multicolumn{4}{r}{} \\
\hline
\end{tabular}

\begin{tabular}{lcccc} 
Risk for depression & 0.66 & 1.94 & $0.99-3.79$ & 0.052 \\
Gender (male) & 0.06 & 1.07 & $0.52-2.17$ & 0.863 \\
\hline Living alone & 0.36 & 1.43 & $0.69-2.94$ & 0.336 \\
High age $(80 \geq)$ & -0.14 & 0.87 & $0.41-1.85$ & 0.724 \\
\hline \multicolumn{5}{l}{ Overall self-determination } \\
\hline
\end{tabular}

\begin{tabular}{lcccc} 
Risk for depression & 1.82 & 6.17 & $2.98-12.78$ & 0.000 \\
Gender (male) & -0.36 & 0.70 & $0.32-1.51$ & 0.359 \\
\hline Living alone & 0.08 & 1.09 & $0.50-2.37$ & 0.836 \\
High age $(80 \geq)$ & -0.16 & 0.86 & $0.38-1.93$ & 0.709 \\
\hline
\end{tabular}


row way of performing the dichotomisation was in line with earlier scientific contributions using the IPA-O to measure older people's self-determination (Ottenvall Hammar, Dahlin-Ivanoff, Wilhelmson, \& Eklund, 2015; Ottenvall Hammar et al., 2016). Further, this decision made it possible to capture people who did not have any doubts of their level of self-determination. Thus, only people perceiving self-determination fully in their daily life were explored in relation to risk of depression, which is a strength.

Several simple logistic regression models were carried out to explore the potential effect risk for depression had on the older people's self-determination. An alternative procedure to explore the associations could have been to use stepwise procedures. However, these procedures have been criticised since the methods have a tendency to miss influential predictors (Harrell, 2001). Furthermore, in some of the regression models, the independent variable risk for depression was combined with demographic variables such as gender, living alone, and high age (age 80 years and older). Nevertheless, it was not possible to create a model based on all the demographic variables combined with risk for depression since the number of participants perceiving reduced self-determination was too small in some dimensions of the IPA-O, such as self-determination in self care and financial situation, which is a possible limitation. Thus, further studies with a larger number of people perceiving reduced self-determination in daily life is warranted to fully understand all the aspects of self-determination and affecting variables.

\section{Conclusions}

Risk for depression affects frail older people's possibilities to exercise self-determination in their daily life when using leisure time, in social relationships, and in one's chances to living the life one wants. The findings points out an increased need of strengthening healthcare professionals' perspectives, and attitudes towards a self-determined, friendly, and person-centred dialogue, where the frail older people's strengths, and what they value in life, shapes the partnership.

\section{References}

Andersson, I., Pettersson, E., \& Sidenvall, B. (2007). Daily life after moving into a care home - experiences from older people, relatives and contact persons. Journal of Clinical Nursing, 16(9), 1712-1718. doi:10.1111/j.1365-2702.2007.01703.x

Breitholtz, A., Snellman, I., \& Fagerberg, I. (2013). Older people's dependence on caregivers' help in their own homes and their lived experiences of their opportunity to make independent decisions. International Journal of Older People Nursing, 8(2), 139-148. doi: 10.1111/j.1748-3743.2012.00338.x

Brink, T. L., Yesavage, J. A., Lum, O., Heersema, P. H., Adey, M., \& Rose, T. L. (1982). Screening tests for geriatric depression. Clinical Gerontologist, 1(1), 37-43.

Ekdahl, A., Andersson, L., Wirehn, A.-B., \& Friedrichsen, M. (2011). Are elderly people with co-morbidities involved adequately in medical decision making when hospitalised? A cross-sectional survey. BMC Geriatrics, 11, 46-54. doi:10.1186/1471-2318-11-46

Ekelund, C., Dahlin-Ivanoff, S., \& Eklund, K. (2014). Self-determination and older people -a concept analysis. Scandinavian Journal of Occupational Therpy, 21(2), 116-124. doi:
$10.3109 / 11038128.2013 .853832$

Ekman, I., Swedberg, K., Taft, C., Lindseth, A., Norberg, A., Brink, E., Carlsson J, Dahlin-Ivanoff S, Johansson IL, Kjellgren K, Lidén E, Öhlén J, Olsson LE, Rosén H, Rydmark M., \& Sunnerhagen, K. S. (2011). Person-centered care-ready for prime time. European Journal of Cardiovascular Nursing, 10(4), 248-251. doi: 10.1016/j.ejcnurse.2011.06.008

Faronbi, J., Gustafsson, S., Berglund, H., Ottenvall Hammar, I., \& Dahlin-Ivanoff, S. (2017). Social Network and Support, SelfRated Health, and Loneliness as Predictors of Risk for Depression Among pre-Frail and Frail Older People in Sweden. OAJ Gerontology \& Geriatric Medicine, 2(5), 555597.

Flick, U., Fischer, C., Neuber, A., Schwartz, F. W., \& Walter, U. (2003). Health in the context of growing old: social representations of health. Journal of Health Psychology, 8(5), 539-556. doi.org/10.1177/13591053030085006

Fried, L. P., Ferrucci, L., Darer, J., Williamson, J. D., \& Anderson, G. (2004). Untangling the concepts of disability, frailty, and comorbidity: implications for improved targeting and care. The Journals of Gerontology. Series A, Biological Sciences and Medical Sciences, 59(3), 255-263.

Gottfries, G. G., Noltorp, S., \& Norgaard, N. (1997). Experience with a Swedish version of the Geriatric Depression Scale in primary care centres. International Journal of Geriatric Psychiatry, 12(10), 1029-1034.

Harrell, F. E. (2001). Regression Modeling Strategies: with applications to linear models, logistic regression, and survival analysis. New York: Springer.

Holstein, B. E., Due, P., Almind, G., \& Avlund, K. (2007). Eightyear change in functional ability among 70- to 95-year-olds. Scandinavian Journal of Public Health, 35(3), 243-249. https://doi.org/10.1080/14034940601072372

Janlöv, A. C., Hallberg, I. R., \& Petersson, K. (2006). Older persons' experience of being assessed for and receiving public home help: Health and Social Care in the Community, 14(1), 26-36. doi.org/10.1111/j.1365-2524.2005.00594.x

Lee, Y., Choi, K., \& Lee, Y. K. (2001). Association of comorbidity with depressive symptoms in community-dwelling older persons. Gerontology, 47(5), 254-262. doi.org/10.1159 /000052809

Levasseur, M., St-Cyr Tribble, D., \& Desrosiers, J. (2009). Meaning of quality of life for older adults: importance of human functioning components. Archives of Gerontology and Geriatrics, 49(2), 91-100. doi: 10.1016/j.archger.2008.08.013

McCormack, B., \& McCance, T. V. (2006). Development of a framework for person-centred nursing. Journal of Advanced Nursing, 56(5), 472-479. doi.org/10.1111/j.1365-2648.2006. 04042.x

Ottenvall-Hammar I, Ekelund C, Wilhelmson K, \& Eklund K. (2014). Impact on Participation and Autonomy - test of validity and reliability for older persons. Health Psyhology Research, 2, 68-73. doi: 10.4081/hpr.2014.1825.

Ottenvall Hammar, I., Dahlin-Ivanoff, S., Wilhelmson, K., \& Eklund, K. (2014). Shifting between self-governing and being governed: a qualitative study of older persons' self-determination. BMC Geriatrics, 14(1), 126. doi: 10.1186/1471-2318-14126

Ottenvall Hammar, I., Dahlin-Ivanoff, S., Wilhelmson, K., \& Eklund, K. (2015). People dependent of support in daily activities perceives reduced self-determination - a cross-sectional study with community-dwelling older people. Quality in Ageing and Older Adults, 16(4):208-221. 
doi.org/10.1108/QAOA-02-2015-0007

Ottenvall Hammar, I., Dahlin-Ivanoff, S., Wilhelmson, K., \& Eklund, K. (2016). Self-determination among communitydwelling older persons: explanatory factors. Scandinavian Journal of Occupational Therapy, 23(3), 198-206. doi: $10.3109 / 11038128.2015 .1126348$

Robeyns, I. (2005). The Capability Approach: a theoretical survey. Journal of Human Development and Capabilities, 6(1), 93177. doi.org/10.1080/146498805200034266

Wilhelmson, K., Duner, A., Eklund, K., Gosman-Hedstrom, G., Blomberg, S., Hasson, H., Gutafsson, H., Landahl, S., \& Dahlin-Ivanoff, S. (2011). Continuum of care for frail elderly people: Design of a randomized controlled study of a multiprofessional and multidimensional intervention targeting frail elderly people. BMC Geriatrics, 11, 24. doi: 10.1186/14712318-11-24

World Health Organization (WHO). (2016). Mental health and older adults [Internet]. Retrieved from http://www.who.int/mediacentre/factsheets/fs381/en/

Yesavage, J. A., Brink, T. L., Rose, T. L., Lum, O., Huang, V., Adey, M., \& Leirer, V. O. (1982). Development and validation of a geriatric depression screening scale: a preliminary report. Journal of Psychiatric Research, 17(1), 37-49. 